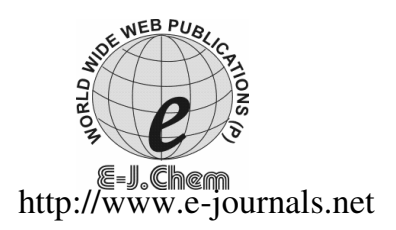

ISSN: 0973-4945; CODEN ECJHAO E-Journal of Chemistry 2010, 7(4), 1407-1411

\title{
Effect of Benzyltrimethylammonium Ion as a Co-directing Agent on Phase Transitions in a Nanostructure Silica/Surfactant Composite
}

\author{
ALIREZA BADIEI ${ }^{*}$, HASSAN GOLDOOZ $^{\S}$ and \\ GHODSI MOHAMMADI ZIARANI
}

\author{
"School of Chemistry, College of Science, University of Tehran, Iran. \\ ${ }^{\S}$ Department of Chemistry, Tarbiat Modares University, Tehran, Iran. \\ Department of Chemistry, Faculty of Science, Alzahra University, Iran \\ abadiei@khayam.ut.ac.ir
}

Received 31 August 2009; Revised 12 January 2010; Accepted 7 March 2010

\begin{abstract}
Effect of benzyltrimethylammonium ion as a co-directing agent in phase transition from hexagonal to cubic and lamellar mesophases was studied in the constant $\mathrm{pH}$ at $130{ }^{\circ} \mathrm{C}$. This phase transformation was carried out in constant surface charge and pore size distribution $(2 \mathrm{~nm})$. Influence of $\mathrm{BTMA}^{+}$ ions between head and tail of surfactant and phase transformation were observed by using the XRD and elemental analysis.
\end{abstract}

Keywords: Benzyltrimethylammonium ion, Co-directing agent, Phase transition, Hexagonal, Cubic, Lamellar.

\section{Introduction}

Order forms of nanoporous materials have been synthesized in a variety of hexagonal, cubic, and lamellar phases through the reaction of inorganic species in the presence of surfactant self-assemblies as supramolecular templates ${ }^{1}$. These materials have attracted vast interest because of their potential application as catalysts ${ }^{2-5}$, solid phase micro extraction (SPME) ${ }^{6,7}$, metal scavengers ${ }^{8}$, preconcentration of metals ${ }^{9,10}$ and in the modified electrodes ${ }^{11-13}$. The more understanding of the formation mechanism should finally lead to a more rational approach to synthesis of mesoporous materials. The proposed models have explained the formation of these materials ${ }^{14}$. In M41S type materials, cationic surfactant molecules and surface silanolates, $\equiv \mathrm{Si}-\mathrm{O}^{-}$, are implicated the so-called $\left\{\mathrm{S}^{+}, \mathrm{I}^{-}\right\}$pathway ${ }^{15}$. In this pathway, the associated silica oligomers with surfactant head groups can polymerize and a highly ordered rigid framework forms. The overall topology of this nanostructure is determined by surfactant curvature which can be described by the dimensionless effective surfactant 
packing parameter $(g)^{16}$. This model explains favored phase transition from lamellar to cubic and hexagonal phases. The effect of lipophilic nature of surfactant counter ion was reported in phase transitions ${ }^{17,18}$. The solid state transformation from MCM-41 to MCM-48 and MCM-50 was recently studied by transmission electron microscopy (TEM) and scanning electron microscopy (SEM) methods ${ }^{19}$. Here, for the first time we reported the effect of benzyltrimethylammonium ion as a co-surfactant for phase transitions from hexagonal to cubic and lamellar.

\section{Experimental}

To prepare the silica source, colloidal silica, Ludox HS40 (Aldrich), was dissolved in $1 \mathrm{M}$ $\mathrm{NaOH}$ at $80{ }^{\circ} \mathrm{C}$ for $8 \mathrm{~h}$. The molar composition of clear solution of sodium silicate was $1 \mathrm{SiO}_{2}: 0.5 \mathrm{NaOH}: 33 \mathrm{H}_{2} \mathrm{O}$. The solution was stored in a polypropylene bottle until used as the silica source.

In a typical synthesis batch, $60 \mathrm{~g}$ of the silica source was slowly added to clear solution of $4.4 \mathrm{~g}$ cetyltrimethylammonium bromide (CTMABr), $10.2 \mathrm{~g}$ benzyltrimethylammonium chloride (BTMACl) (60\% in water) (Aldrich) and $57.1 \mathrm{~g}$ distilled water with vigorous magnetic stirring for $30 \mathrm{~min}$. The resulting gel, with a molar composition of $1 \mathrm{SiO}_{2}: 0.13$ CTMABr: 0.35 BTMACl: $66.30 \mathrm{H}_{2} \mathrm{O}$, was mixed for $1 \mathrm{~h}$, then it was heated at $130{ }^{\circ} \mathrm{C}$ in a Teflon-lined autoclave for $24-120 \mathrm{~h}$. The amount of surface silanolate groups $\left(\mathrm{SiO}^{-} / \mathrm{SiO}_{2}\right)$ was determined by acid-base titration as described in details earlier ${ }^{20}$. The weight loss was measured after calcination at $550{ }^{\circ} \mathrm{C}$. The amount of $\mathrm{CTMA} / \mathrm{SiO}_{2}$ was determined by spectrophotometer as described in details earlier ${ }^{20}$. The total amount of $\mathrm{Cl}^{-}$and $\mathrm{Br}^{-}$was determined by conductomertic titration of $0.01 \mathrm{M}$ silver nitrate solution.

\section{Characterization techniques}

The nitrogen adsorption-desorption isotherms were measured at $-196{ }^{\circ} \mathrm{C}$ using a Belsorp mini-II system. The samples were vacuum dried at $150{ }^{\circ} \mathrm{C}$ overnight. The powder x-ray diffractograms were recorded by Bruker AXS D8 diffractometer with nickel filtered $\mathrm{Cu}-\mathrm{K} \alpha$ $(\lambda=1.5418 \AA)$ where the $\mathrm{x}$-ray tube was operated at $40 \mathrm{KV}$ and $30 \mathrm{~mA}$, the spectra were scanned at 0.02 step size.

\section{Results and Discussion}

Figure 1 shows the small angle x-ray diffraction patterns of as-made and calcined silica mesophases at $130{ }^{\circ} \mathrm{C}$ for $24,48,72$ and $120 \mathrm{~h}$ reaction times. The phase transformation of silica mesophase was observed with the increasing of reaction time of gel according to small angel x-ray diffraction patterns. After $24 \mathrm{~h}$ of the reaction time (so-called MTS-24 h), three diffraction peaks were observed that can be indexed to a $16 \mathrm{~mm}$ two-dimensional hexagonal phase (MCM-41 type). When this sample (MTS-24 h) was calcined at $550{ }^{\circ} \mathrm{C}$, the $(100)$ reflection was shifted to high angle and the FWHM (Full Width at Half-Maximum) of the reflection increases. This observation can be attributed to the $19 \%$ shrinkage of the silica walls as previously reported for MCM- $41^{21}$. It can be due to lower condensation of silica framework and the partial collapse of the hexagonal ordered phase ${ }^{21}$. After $48 \mathrm{~h}$ hydrothermal treatment (so-called MTS-48h), the XRD showed the diffraction patterns of cubic nanostructure (MCM-48 type) with Ia3d space group. All characterization peaks of hexagonal array were disappeared at this reaction time. The XRD patterns of calcined MTS$48 \mathrm{~h}$ indicated that the (211) reflection was shifted to the high angle and the nanostructure cubic phase was stable after removal of the surfactant. On the other hand, the intensity 
increases in the XRD reflections that correspond to high order cubic phase with $10 \%$ shrinkage of silica framework. However, it shows that there is higher condensation of silica framework in the cubic phase than in the hexagonal phase. Therefore, this process can be due to change of silica walls curvature in nanostructure mesophase. This curvature depends on the packing factor $(g)$ of directing agent and the surface charge on silica surface ${ }^{17,20}$. When BTMA ${ }^{+}$ions are not presence in the composition reaction, this phase transformation did not observe and the hexagonal phase was obtained. Therefore, $\mathrm{BTMA}^{+}$ions have an important role as a co-directing agent. This effect was observed when the gel was treated for more time $(72 \mathrm{~h})$ (so-called MTS-72 h), the intensity of $\mathrm{d}_{211}$ reflection was decreased and lamellar phase was appeared (peak at $2 \theta=2.7$ degree). The lamellar phase collapsed when the directing agent (surfactant) was calcined at high temperature or was removed during the treatment with acid in ethanol ${ }^{1}$. Thus, the characterization peak of this phase was not observed in XRD pattern after calcination. Finally, the pure lamellar phase with two diffraction peaks (MCM-50 type) was observed in the XRD pattern after $120 \mathrm{~h}$ (so-called MTS-120 h). The two characterization peaks of MTS-120 $\mathrm{h}$ were disappeared after calcination.

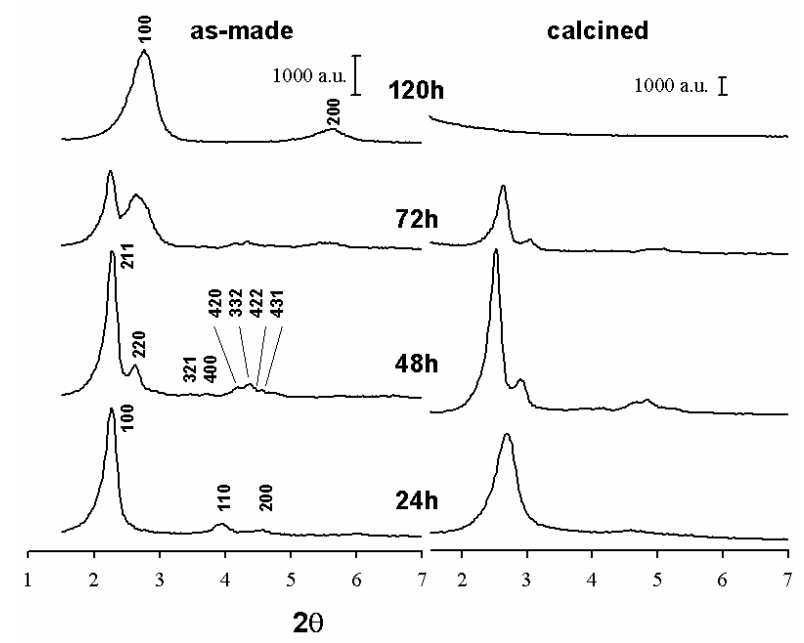

Figure 1. Small angle powder XRD patterns of as-made (left) and calcined (right) silica mesophases obtained at $130{ }^{\circ} \mathrm{C}$ for $24,48,72$ and $120 \mathrm{~h}$ reaction times

It is necessary to calculate the amount of $\mathrm{BTMA}^{+}$ions in the solids to understand why phase transformation from a higher-curvature hexagonal phase is preferred to a lowercurvature lamellar phase in the presence of $\mathrm{BTMA}^{+}$ions during the reaction time. Table 1 shows the chemical analysis of the as-made silica nanostructure. The final $\mathrm{pH}$ of all samples and the obtained silanolate $\left(\mathrm{SiO}^{-} / \mathrm{SiO}_{2}\right)$ were approximately very close. The quantity of $\mathrm{CTMA}^{+}$on the surface was decreased with increase of the reaction time. At the same time, the phase transfers from hexagonal to lamellar, as mentioned above. In contrast, an augmentation was observed for the percentage of anions $\left(\mathrm{Cl}^{-}\right.$and $\left.\mathrm{Br}^{-}\right)$, but with small variations (about $0.2 \%$ for each transition phase). In this chemical analysis, there is a deficit in positive charges that could be attributed to both $\mathrm{BTMA}^{+}$and $\mathrm{Na}^{+}$. However, the concentration of sodium is very low (at the detection limit of atomic absorption technique) and accounts for less than $0.1 \% \mathrm{Na}^{+} / \mathrm{SiO}_{2}$. Therefore, the deficit is mainly compensated by $\mathrm{BTMA}^{+}$ion. The percentage of $\mathrm{BTMA}^{+}$is increased from hexagonal to lamellar mesophase (about $1 \%$ for each transition phase). 
Table 1. Chemical analysis of as-made silica mesophase obtained with titration of $0.1 \mathrm{~N} \mathrm{HCl}$ in absolute ethanol

\begin{tabular}{ccccccc}
\hline & $\begin{array}{c}\mathrm{pH}_{\text {final }} \\
\pm 0.1\end{array}$ & $\begin{array}{c}\mathrm{SiO}^{-} / \mathrm{SiO}_{2} \\
\pm 0.1 \%\end{array}$ & $\begin{array}{c}\mathrm{X}^{-} / \mathrm{SiO}_{2}{ }^{\mathrm{a}} \\
\pm 0.1 \%\end{array}$ & $\begin{array}{c}\mathrm{CTMA}^{+} / \mathrm{SiO}_{2} \\
\pm 0.1 \%\end{array}$ & $\begin{array}{c}\Delta \Sigma^{ \pm \mathrm{b}} \\
\pm 0.3 \%\end{array}$ & $\begin{array}{c}\mathrm{a}_{\mathrm{o}}{ }^{\mathrm{c}} \\
\pm 0.1(\mathrm{~nm})\end{array}$ \\
\hline MTS-24 h & 10.3 & 22.7 & 1.0 & 22.5 & 1.2 & 2.1 \\
MTS-48 h & 10.2 & 22.2 & 1.2 & 20.7 & 2.7 & 2.2 \\
MTS-72 h & 10.5 & 22.1 & 1.3 & 20.0 & 3.4 & 2.2 \\
MTS-120 h & 10.6 & 22.3 & 1.5 & 19.2 & 3.6 & - \\
\hline
\end{tabular}

${ }^{a} \mathrm{X}^{-}=\mathrm{Cl}+\mathrm{Br}^{-},{ }^{b}$ Charge deficit (missing positive charge per $\mathrm{SiO}_{2}$ ), ${ }^{c}$ Average pore diameter calculated by $B J H$ method

The phase transition can be understood by applying the simple model of Israelachvili on the conical shape and the space occupied by the hydrophilic and hydrophobic groups of the surfactant ${ }^{16,22}$. The local effective parameter is defined as $g=V / a_{0} l_{c}$, where $V$ and $l_{c}$ are the total volume and the length of the hydrophobic portion of the surfactant and $\mathrm{a}_{0}$ is the polar head area. The aggregate structure depends on the value of the $g$ : the larger the $g$, the less curvature in the aggregate. The increased tail motion changes the effective volume and shape occupied by a surfactant. In this mesophase transition, over time some $\mathrm{BTMA}^{+}$ diffuses between of head and tail of surfactant and increase the V (Figure 2) and mobility of tail, which in turn increases the $g$ and favored mesophase with a lower curvature. However, for the repulsion decreasing between $\mathrm{BTMA}^{+}$and head group of surfactant, the presence of anions was probably admitted beside of $\mathrm{BTMA}^{+}$. Penetration of anion leads to a closer Helmholtz planes and a better screening of the positive charges that allows the ammonium heads to move closer one to another and to have a smaller surface area for the same occupied space by the alkyl chains ${ }^{17}$. However, the silica framework limits the available space, and thus, surfactants are unable to occupy their preferred volume and/or attain their preferred curvature; the surfactant volume and/or curvature become frustrated. Eventually this packing frustration overcomes the strength of the covalent bonds in the silica network, and the hexagonally packed nanostructure silica transform to lamellar silica (Figure 2).

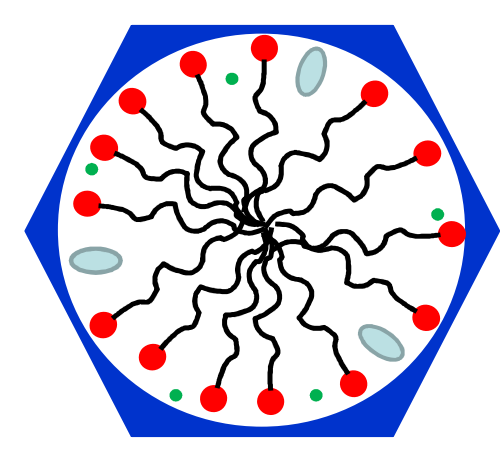

Hexagonal nanostructure

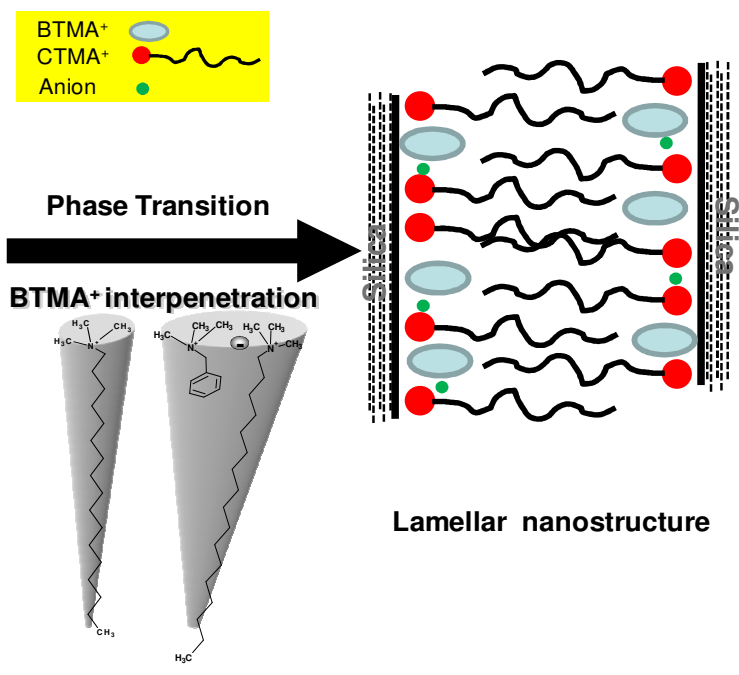

Figure 2. Influence of $\mathrm{BTMA}^{+}$between head and tail of surfactant and volume increasing, and phase transition from hexagonal to lamellar nanostructure 


\section{Conclusion}

In conclusion, it was shown that in the nanostructure mesophase synthesis under constant $\mathrm{pH}$ conditions, $\mathrm{BTMA}^{+}$ions diffuses between the head and the tail of the surfactant and phase transition occurs from hexagonal to cubic and lamellar mesophases at $130{ }^{\circ} \mathrm{C}$. In this transformation the charge of surface and the pore size $(2 \mathrm{~nm})$ were constant.

\section{Acknowledgment}

This work was financially supported by University of Tehran.

\section{References}

1. Beck J S, Vartuli J C, Roth W J, Kresge C T, Leonowicz M E, Schmitt K D, Chu C T-W, Olson D H, Sheppard E W, McCullen S B, Higgins J B and Schlenker J L, J Am Chem Soc., 1992, 114, 10834.

2. Trong On D, Desplantier-Giscard D, Danumah C and Kaliaguine S, Appl Catal A: Gen., 2001, 222, 299.

3. Gholami J, Badiei A, Abbasi A and Mohammadi Ziarani G, Int J Chem Tech Res., 2009, 1(3), 426.

4. Badiei A, Gholami J and Khaniani Y, E- J Chem., 2009, 6, S324.

5. Darabi H R, Aghapoor K, Mohsenzadeh F, Taala F, Asadollahnejad N and Badiei A Catal Lett., 2009, 133, 84-89.

6. Hashemi P, Shamizadeh M, Badiei A, Ghiasvand A R and Azizi K, Chromatographia 2009, 70, 1147-1151.

7. Hashemi P, Shamizadeh M, Badiei A, Poor P Z, Ghiasvand A R and Yarahmadi A, Anal Chem Acta, 2009, 646(1-2), 1-5.

8. Bibby A and Mercier L, Chem Mater., 2002, 14, 1591-1597.

9. Gangali M R, Hajiagha Babaei L, Badiei A, Mohammadi Ziarani G and Tarlani A, Anal Sci., 2004, 20, 725.

10. Ganjali M R, Daftari A, Hajiagha Babaei L, Badiei A, Saberyan K, Mohammadi Ziarani G and Moghimi A, Wat Air Soil Pollut., 2006, 173, 71.

11. Javanbakht M, Badiei A, Ganjali M R, Norouzi P, Hasheminasab A and Abdouss M Anal Chim Acta, 2007, 601(2), 172-182.

12. Javanbakht M, Khoshsafar H, Ganjali M R, Badiei A, Norouzi P and Hasheminasab A, Curr Anal Chem., 2009, 5, 35.

13. Javanbakht M, Divsar F, Badiei A, Fatollahi F, Khaniani Y, Ganjali M R, Norouzi P, Chaloosi M and Ziarani G M, Electrochim Acta, 2009, 54, 5381.

14. Ying J Y, Mehnert C P and Wong M S, Angew Chem Int Ed., 1999, 38, 57.

15. Monnier A, Schuth F, Huo Q, Kumar D, Margolese D, Maxwell R S, Stuky G D, Krisnamurthy M, Petroff P, Firouzi A, Janicke A and Chmelka B F, Science, 1993, 261, 1299.

16. Lapena A M, Gross A F and Tolbert S H, Langmuir, 2005, 21(1), 470-480.

17. Echchahed B, Morin M, Blais S, Badiei A, Berhault G and Bonneviot L, Micro Mesopor Mater, 2001, 53, 44.

18. Badiei A, Vahidifar R and Hasheminasab A, Iran J Chem Chem Eng., 2008, 27, 1.

19. Diaz I, Perez-Pariente J and Terasaki O, J Mater Chem., 2004, 14, 48.

20. Badiei A, Morin M, Cantournet S and Bonneviot L, Langmuir, 1998, 14, 7087.

21. Gomez S, Giraldo O, Garces L J, Villegas J and Suib S L, Chem Mater., 2004, 16, 2411.

22. Israelachvili J N, Mitchell D J and Ninham B W, J Chem Soc Faraday Trans., 2, 1976, 72, 1525. 


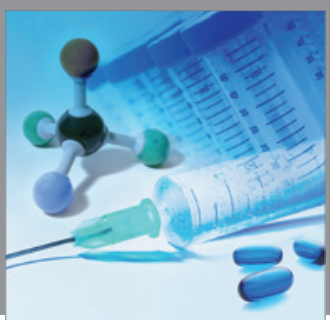

International Journal of

Medicinal Chemistry

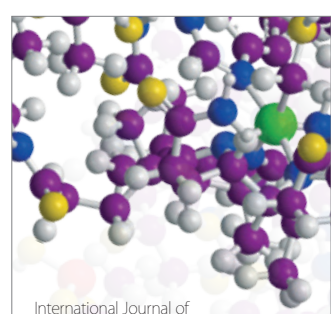

Carbohydrate Chemistry

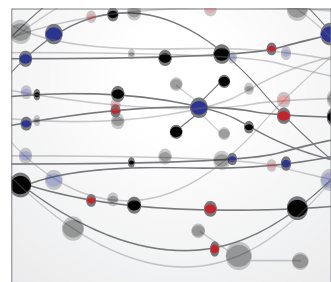

The Scientific World Journal
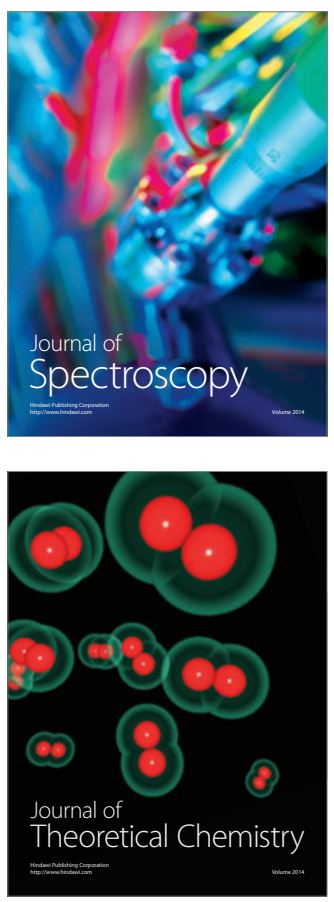
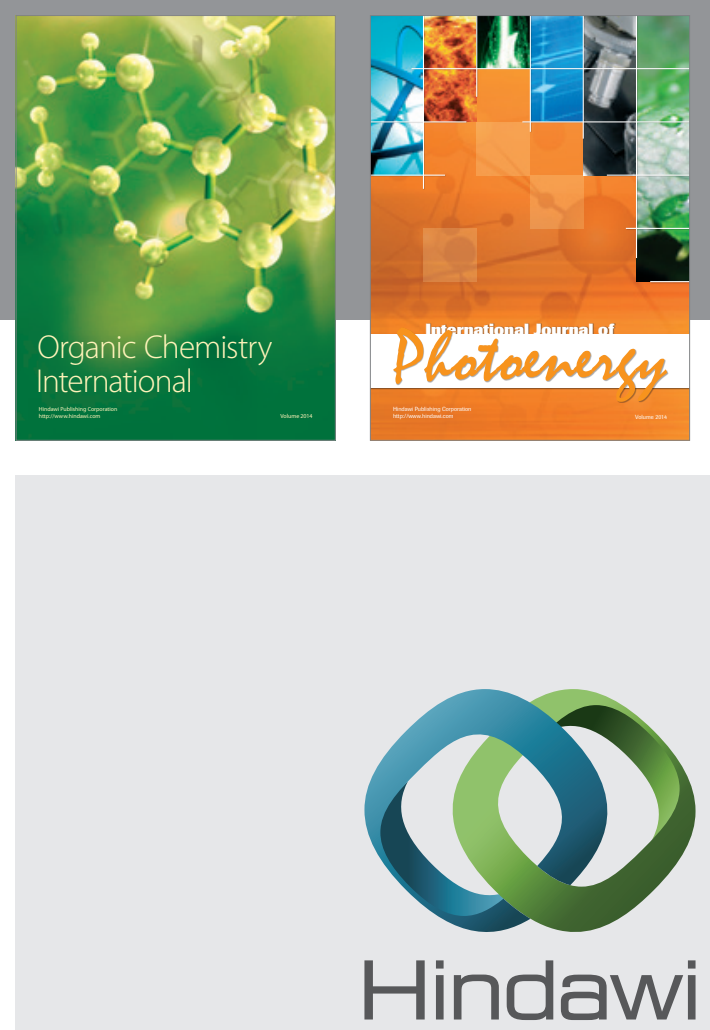

Submit your manuscripts at

http://www.hindawi.com
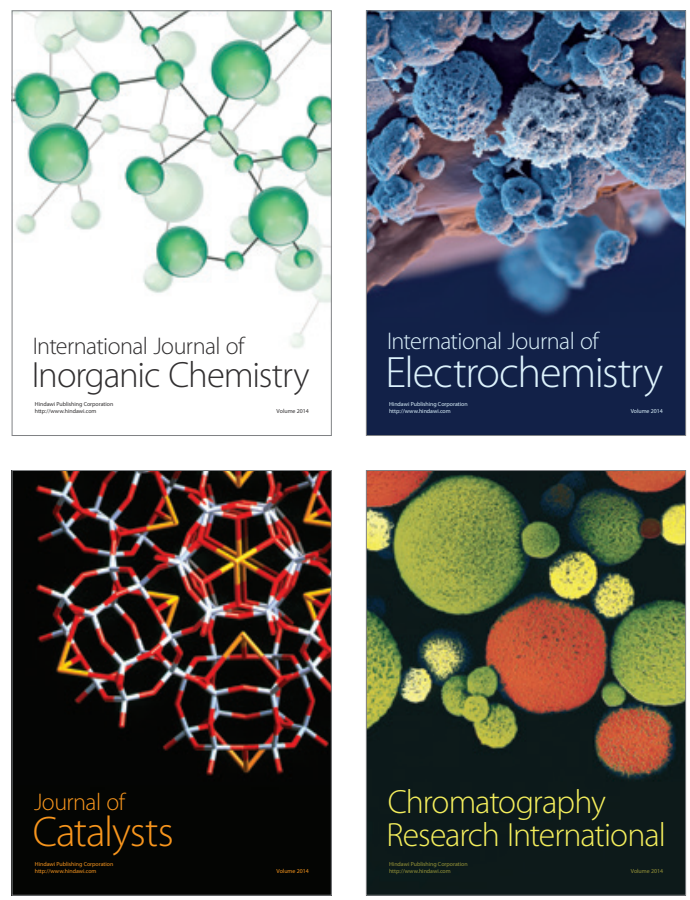
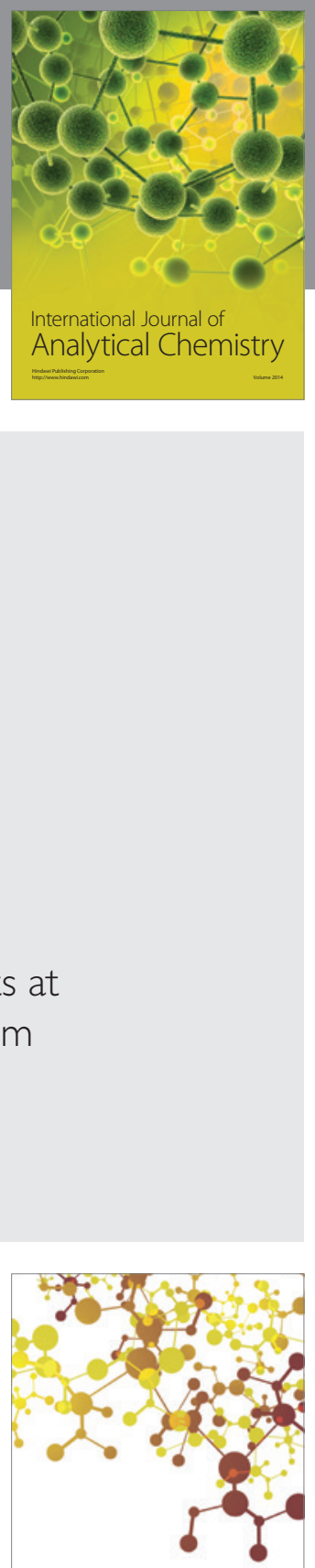

Journal of

Applied Chemistry
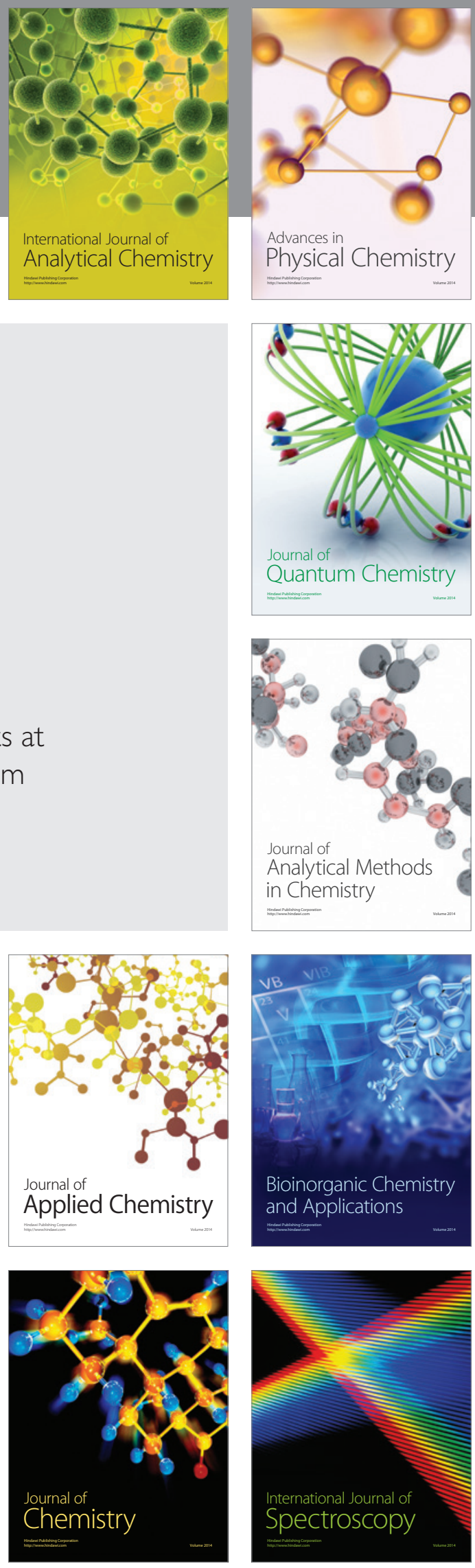